\title{
Evaluation of adhesion of epoxy resin sealant to improve the corrosion resistance of thermal sprayed coatings
}

\author{
Mateus R. D. Carneiro ${ }^{1}$, Bruno C. Freitas ${ }^{1}$, Iuri B. de Barros², José B. de Campos ${ }^{3^{*}}$ (D), Ivan N. Bastos² \\ and Hector R. M. Costa'
}

*Correspondence:

brant@uerj.br;

brantjose@gmail.com

3 Departamento de

Engenharia Mecânica,

Universidade do Estado

do Rio de Janeiro, Rua

Fonseca Teles, 121, São

Cristóvão, Rio de Janeiro, RJ

20.940-903, Brazil

Full list of author information

is available at the end of the

article

\begin{abstract}
The adhesion of coatings on a given substrate has fundamental importance on a coating/substrate system's functionality. The current paper presents the adhesion strength results of $\mathrm{FeCr}$ and $\mathrm{CoCr}$-based deposits produced by the electric arc thermal spray process on carbon steel, with an intermediate layer of 95Ni5 Al. Three chemical compositions were tested for coating deposition and were characterized using plate and tube specimens made of carbon steel UNS G10200 to result in a screening of performance. Microstructural evaluation by optical microscopy (OM), scanning electron microscopy (SEM), and X-ray diffraction (XRD) were performed. Coating strength was measured using the standard pull-off test method. The corrosion resistance was analyzed with salt spray exposure, electrochemical polarization, and impedance spectroscopy (EIS) tests. The adhesion strength of $\mathrm{FeCr}$ and $\mathrm{CoCr}$ alloy coatings shows an overall average tensile strength of 27.2 MPa. All sealed conditions presented low corrosion and the samples with epoxy sealant exhibited a high resistance against corrosion. The X-ray diffraction results have revealed alpha and gamma FeCr alloys and chromite as deposited phases after the coating process.
\end{abstract}

Keywords: Sealants, Thermal spray, Salt spray test, Adhesion test, FeCr, CoCr coatings

\section{Introduction}

The thermal spray process (TS) is an energy and resource-intensive manufacturing process, which thermal energy is generated from electrical plasma/arc or fuel combustion [1]. These energy sources are used to heat the coating material as a powder or suspension form to a molten state $[2,3]$. Coating systems should also possess good mechanical, thermal shock resistance, adhesion, and strain compliance to meet the durability requirements [4]. In these cases, pores and coating imperfections also reduce corrosion and wear resistance. Various post-treatment processes can improve the characteristics of thermal sprayed coatings [3, 5-7]. Ali et al. [8] reported that thermal treatment is an essential post-treatment method for thermal spray coatings. The main effect is the change of phase composition of the as-deposited non-equilibrium toward the equilibrium state. Moreover, thermal spray changes the residual stress state, the densification

(c) The Author(s) 2020. This article is licensed under a Creative Commons Attribution 4.0 International License, which permits use, sharing, adaptation, distribution and reproduction in any medium or format, as long as you give appropriate credit to the original author(s) and the source, provide a link to the Creative Commons licence, and indicate if changes were made. The images or other third party material in this article are included in the article's Creative Commons licence, unless indicated otherwise in a credit line to the material. If material is not included in the article's Creative Commons licence and your intended use is not permitted by statutory regulation or exceeds the permitted use, you will need to obtain permission directly from the copyright holder. To view a copy of this licence, visit http://creativeco mmons.org/licenses/by/4.0/ 
by sintering, and the cross-diffusion of elements between the coating and the substrate $[9,10]$.

The excellent adhesion of coatings on a given substrate is fundamental for a coating/ substrate system's functionality. Different adhesion testing procedures were developed due to a considerable variety of coating/substrate material systems, thickness range, and final product applications [1]. Hence, thermal spray coatings have increased, and coating characterization is critical for understanding the mechanical behavior and improving coating performance [10]. Sealants can also be used to provide surfaces with non-adhesive characteristics (PTFE based sealers). The performance of sealed surfaces is generally superior to unsealed ones; however, the evaluation of corrosion resistance in a given environment after this treatment is always necessary [11]. TS is applied to produce a barrier against abrasion and adhesion under low loading conditions and against corrosion. Good cohesion of deposit and high adherence of the coating on a substrate can be achieved, and those coatings are suitable for in-service use [12]. Conversely, if the adhesion is insufficient, a common choice is the coating alloy system's change.

The adhesive strength was evaluated for five electric arc sprayed coatings based on $\mathrm{FeCr}$ and $\mathrm{CoCr}$ metallic systems in the present investigation. The use of sealants is an attractive alternative for severe condition applications. Thus, the effect of sealing treatment on the corrosion resistance of thermal sprayed coatings in a marine atmosphere was studied. The sealing agent covered the surface and permeated the original defects of the outer as-sprayed coating. Furthermore, the microstructural, adhesion, and corrosion aspects of coatings deposited over carbon steel substrates were also studied.

\section{Experimental}

Samples made of carbon steel UNS G10200 (tube and flat specimens) were machined to produce $4.5 \times 100 \times 150 \mathrm{~mm}$ flat specimens (Fig. 1a). Tubes with $65.5 \mathrm{~mm}$ diameter and $5.0 \mathrm{~mm}$ wall thickness in not-machined (Fig. 1b) and machined (Fig. 1c) conditions were also used. These shapes correspond to real structures where the TS can be applied. The coatings were prepared by an electric arc thermal spray process on carbon steel plates with $20 \mu \mathrm{m}$ grit $\mathrm{Al}_{2} \mathrm{O}_{3}$ blasted surfaces. Initially, an intermediate bond was applied to increase the adhesion of the coating. Pure argon gas was used as the powder carrying and the shielding atmosphere. All the process parameters, including the spray distance, were kept constant throughout the coating process. Coatings were formed by thermally spraying-based alloy using a system manufactured by Praxair TAFA. The parameters used for thermal spraying for both $\mathrm{Cr}-\mathrm{Ni}-\mathrm{Mn}$ and $\mathrm{Co}-\mathrm{Ni}-\mathrm{Mn}$ were as follows: voltage of $40 \mathrm{~V}$, current intensity of $100 \mathrm{~A}$, deposition rate of $2.34 \mathrm{~g} \cdot \mathrm{h}^{-1}$, and pistol distance (circa $100 \mathrm{~mm}$ ). The equipment has two entrances for $2.6 \mathrm{~mm}$ diameter wire reels. After deposition, some samples were sealed with epoxy resin with polyamide having a specific mass of $1.45 \mathrm{~g} / \mathrm{cm}^{3}$, and cured for $24 \mathrm{~h}$. This sealant blocks the porosity that could connect the corrosive environment to the carbon steel substrate. Another group of samples was tested without epoxy application.

Three different wires were used, and their chemical compositions are depicted in Table 1. Wire C is a cobalt alloy, and A and B are ferrous-based alloys. From the possible combinations of wires, intermediate bonds, and type of samples (plate, tube machined and not machined), six combinations were chosen, as shown in Table 2. 


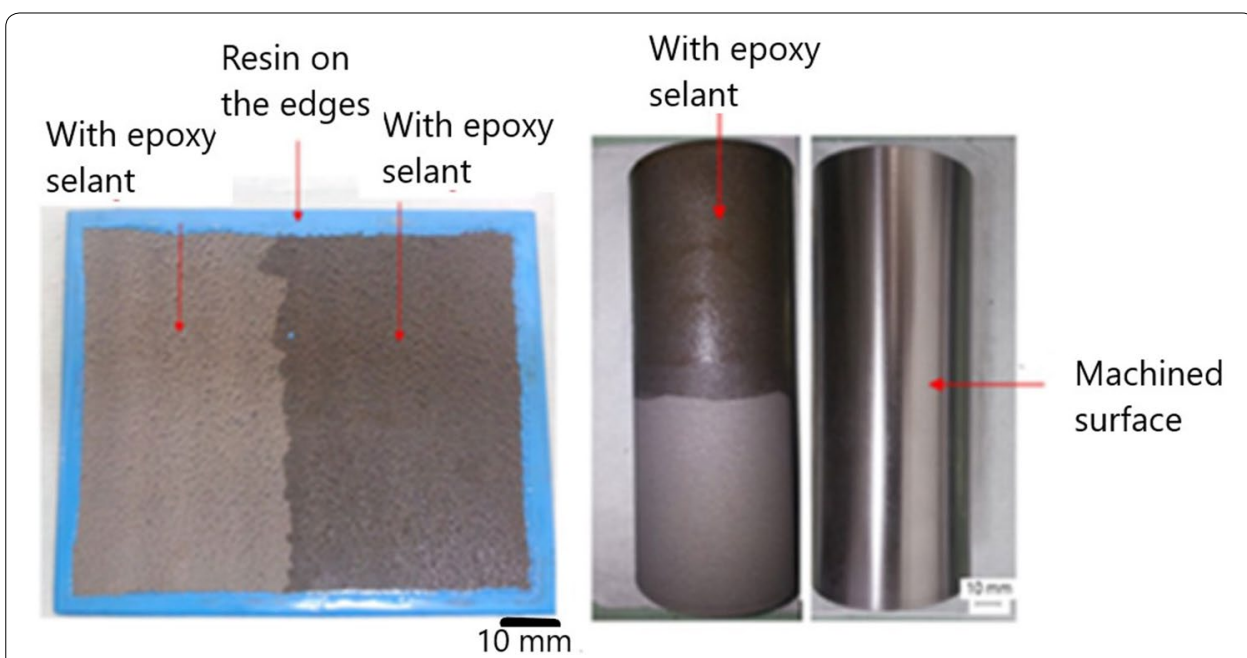

Fig. 1 Coated surface with/without sealant before adhesion and salt spray tests: a Plate sample, b Tube with coating, and c Machined tube coating surface

Table 1 Chemical composition (\% weight) of wires used in electric arc process

\begin{tabular}{lcccccccccc}
\hline Wire & Fe & Co & Cr & Ni & B & Mn & W & Mo & C & Si \\
\hline A & 66.1 & & 27.0 & & 3.5 & 1.8 & & & & 1.6 \\
B & 65.7 & & 25.7 & 2.9 & & 1.9 & & 0.8 & 1.6 & 1.4 \\
C & 3.6 & 58.4 & 28.8 & 1.9 & & 0.9 & 4.9 & 0.02 & 1.1 & 0.3 \\
\hline
\end{tabular}

Table 2 Condition and combination of wires. All intermediate bonds have the same composition 95Ni5Al

\begin{tabular}{lll}
\hline Condition & Combination of wires & Sample \\
\hline 1 & A $+C$ & Plate \\
2 & $A+B$ & Plate \\
3 & $A+C$ & Tube/ achined \\
4 & $A+B$ & Tube/ achined \\
5 & A C & Tube/not machined \\
6 & A B & Tube/not machined \\
\hline
\end{tabular}

Just one intermediate bond was chosen, an ordinary $95 \mathrm{Ni} 5 \mathrm{Al}$ that produces a known good adherence. For simplicity, each combination of the wire-intermediate bond was termed Condition 1 to 6 , as depicted in Table 2 .

The coating porosity and layer thickness were evaluated by using an optical microscope coupled with image analysis processing. The average percentage of porosity was obtained by analyzing ten image frames located at three positions of each sample using the software Fiji-Image J.

A pull-off test was conducted by applying a tensile stress perpendicular to the surface and was performed according to the ASTM D4541-17 standard [13]. The tests were performed in duplicate. The sample was attached to the loading holder and then 
aligned before the application of normal stress. The load increases gradually, and it is monitored up to the instant of onset of a detachment of coating, or when a previously specified nominal stress is reached. Fractography and microstructures were evaluated by scanning electron microscopy-SEM. Some samples were mounted with Bakelite for metallographic examination. The coating cross-sections' microstructural and morphological characteristics were studied using an Olympus BX60MF Optical Microscope (OM) and a CamScan 3200LS Scanning Electron Microscope (SEM). SEM microscope had X-ray Energy-Dispersive System (EDX) microanalysis with spectral mapping and element point facilities. The samples for microscopic examination were prepared by standard metallographic techniques.

Phase characterization was performed by X-Ray Diffraction-XRD technique using a Panalytical X'Pert Pro diffractometer with $\mathrm{Cu} K \alpha$-radiation. A scanning step of 0.05 degree and a collecting time of $300 \mathrm{~s}$ per step was used. Semiquantitative Rietveld calculations [14] were done using Topas Academic version 4.1 [15] for phase determination. For these calculations, the lattice parameter, the crystalline size, and the scale were adjusted, and the quantification of crystalline phases was determined.

Electrochemical measurements were performed in a three-electrode cell assembly at laboratory room temperature. The metallic samples were the working-electrode, and saturated calomel electrode (SCE) used as a reference electrode, the counter-electrode was a large area platinum wire. The electrolyte was a $3.5 \%$ wt. sodium chloride aqueous solution prepared with analytical grade reagent (Vetec Fine Chemicals Ltda, Brazil) and deionized water. All electrochemical measurements were carried out using Princeton Applied Research (USA) potentiostat, model VersaSTAT 3, with the software VersaStudio. The electrochemical tests were applied to the flat samples of Conditions 1 and 2 (Table 2). The working-electrode with a large circular area of $23 \mathrm{~cm}^{2}$ was used in the electrochemical tests, and with the surface produced by thermal spray.

The evolution of open circuit potential (OCP) was monitored for up to two hours. After this period, the electrochemical impedance spectroscopy (EIS) measurement was performed over a frequency range of $20 \mathrm{kHz}-5 \mathrm{MHz}$. EIS was measured at the steadystate potential with an a.c. wave of $10 \mathrm{mV}_{\mathrm{RMS}}$ and 10 points per decade. Subsequently, the polarization curves were performed from the cathodic to the anodic direction from - $100 \mathrm{mV}$ below the open-circuit potential up to $1000 \mathrm{mV}$ above it, with a scan rate of $1.0 \mathrm{mV} \cdot \mathrm{s}^{-1}$.

Samples of coated carbon steel were tested in a salt spray chamber at $35^{\circ} \mathrm{C}$ for $36 \mathrm{~h}$. An aqueous 5.0\% sodium chloride solution was used as an electrolyte in the salt spray chamber. After the exposure, the analysis of SEM images estimated the evaluation of the corroded area. An epoxy resin was used to protect the specimen edges during the salt spray test (Fig. 1a).

\section{Results and discussion}

SEM images of the coating layer produced by thermal spray are depicted in Fig. 2 and 3. Metallic coatings with $\mathrm{Co}-\mathrm{Ni}$ and $\mathrm{Cr}-\mathrm{Ni}$ compositions exhibited distinct splats or lamellae due to the impact during the thermal spray process. There are some microcracks, but the addition of alloying elements has significantly improved the features of the coatings. For instance, fewer cracks are present in the coating layers containing cobalt, and the 


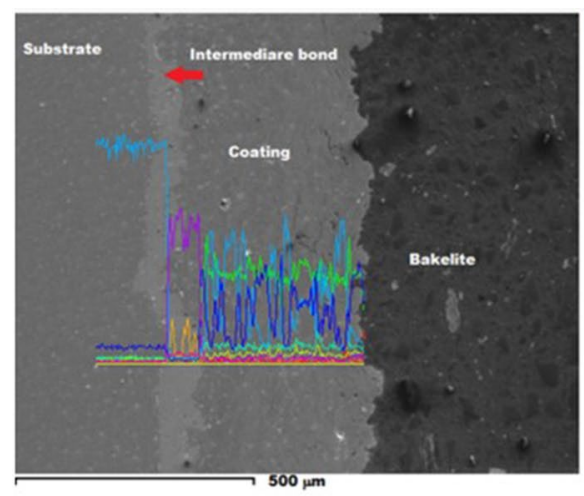

a

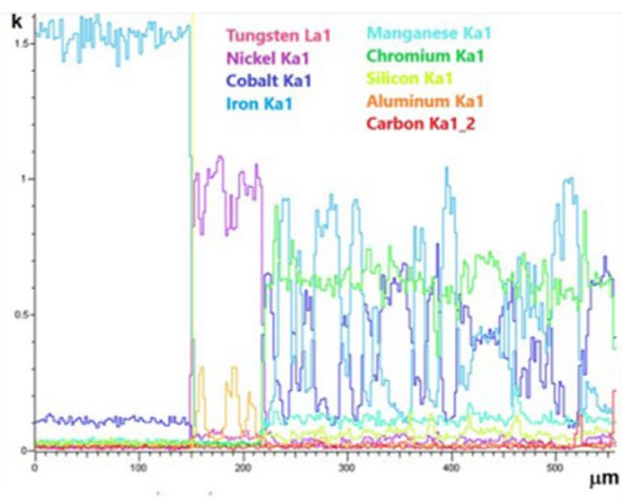

b

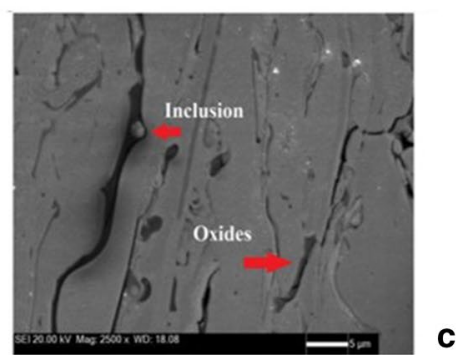

Fig. 2 SEM micrographs reveal the presence of microcracks, porosity, and oxides. Line (Fig. 2b) analysis by EDX spectra reveals the element presence. Condition 1

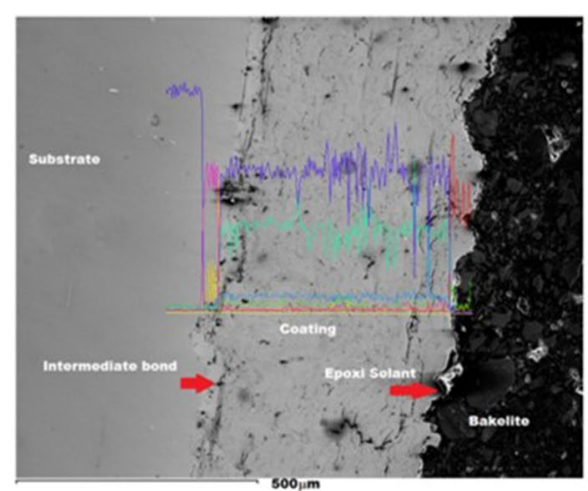

a

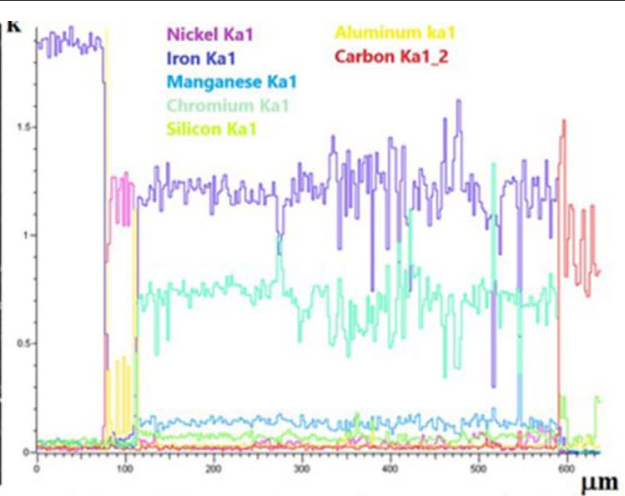

b

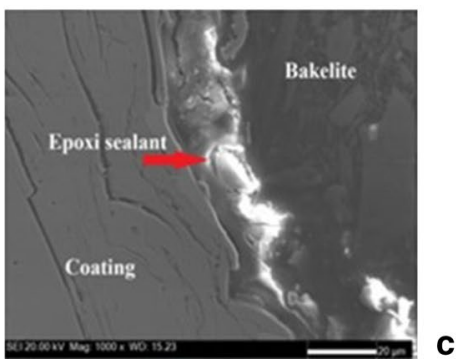

Fig. 3 SEM micrographs. Presence of microcracks, porosity, and epoxy sealant. Line (Fig. 3b) analysis by EDX spectra reveals the elemental distribution. Condition 2 


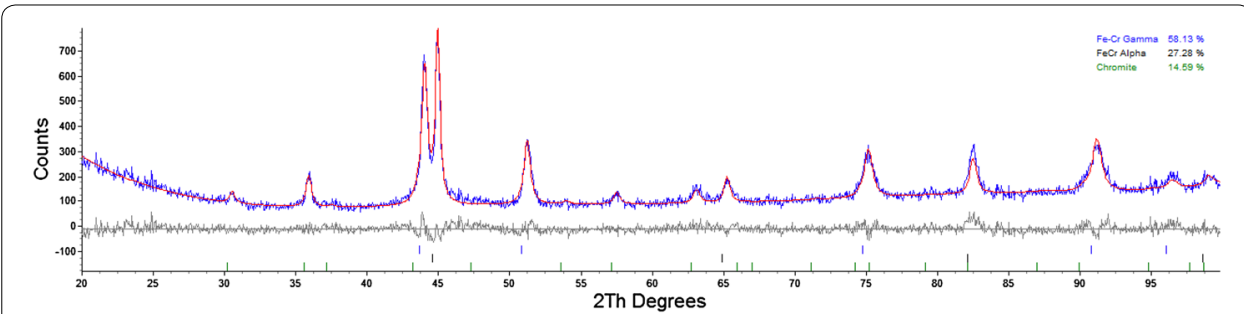

Fig. 4 X-ray diffraction Rietveld fitting for the coating Condition 1

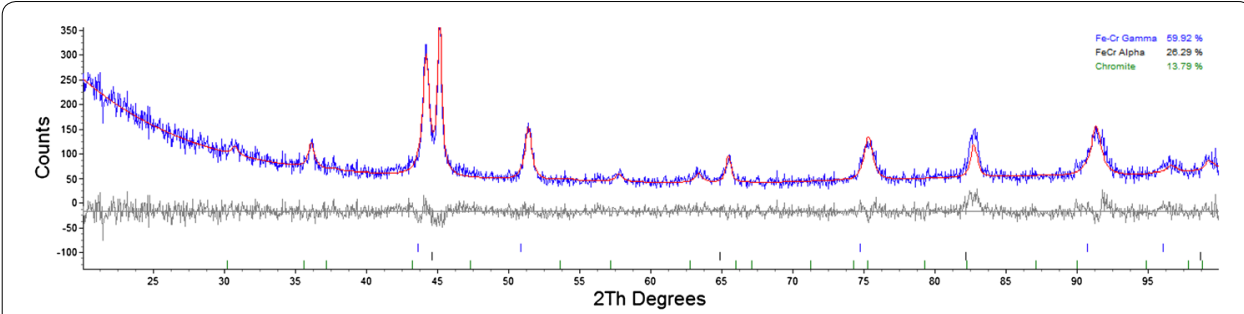

Fig. 5 X-ray diffraction Rietveld fitting for the coating Condition 2

overall coating microstructure is homogeneous with few closed porosities along lamella boundaries. This type of structure resulted from the deposition of successive layers. The lamellar structure is anisotropic, and dependency of properties with respect at the directions parallel to the substrate and transverse to the coating thickness is expected [16]. The deposition process's choice depends strongly on the expected coating properties for the application and the coating cost. Coating properties are determined by the materials, shape, and the parameter settings of the deposition process [17].

EDX results indicate the substrate/coating interface (Fig. 2 and 3) for all conditions. Line analysis shows the element content along the substrate and the coating. Some dispersions in the element content are noted in the coating. Moreover, the sprayed coatings structure is heterogeneous due to the scattering of individual particle impact caused by local cooling and flow conditions during the deposition [10]. The total defect level of the coatings was quantified using an image analysis technique. Although the mean value obtained for Condition 1 (3.87\%) is more significant than Condition 2 (3.28\%), the relative difference between the two values $(0.59 \%)$ is small. The results' dispersion is very similar since the standard deviation differs by only $0.01 \%$ when comparing Conditions 1 and 2 . This result agrees with other authors [14, $15]$ who found a range of $0.2-10.0 \%$ for porosity in electric process deposition. The chemical composition of wires did not affect the defect level. Generally, the porosity of thermal spray coatings is typically less than $5 \%$ of volume. However, this porosity affects the heat transfer of specific mechanical components [18] that can be a critical aspect for specific applications [19].

Figures 4 and 5 show the X-ray diffraction with Rietveld calculations of the Conditions 1 and 2. The blue line corresponds to the experimental data, the red one corresponds to the calculated spectrum, and the gray line is the difference between them. 


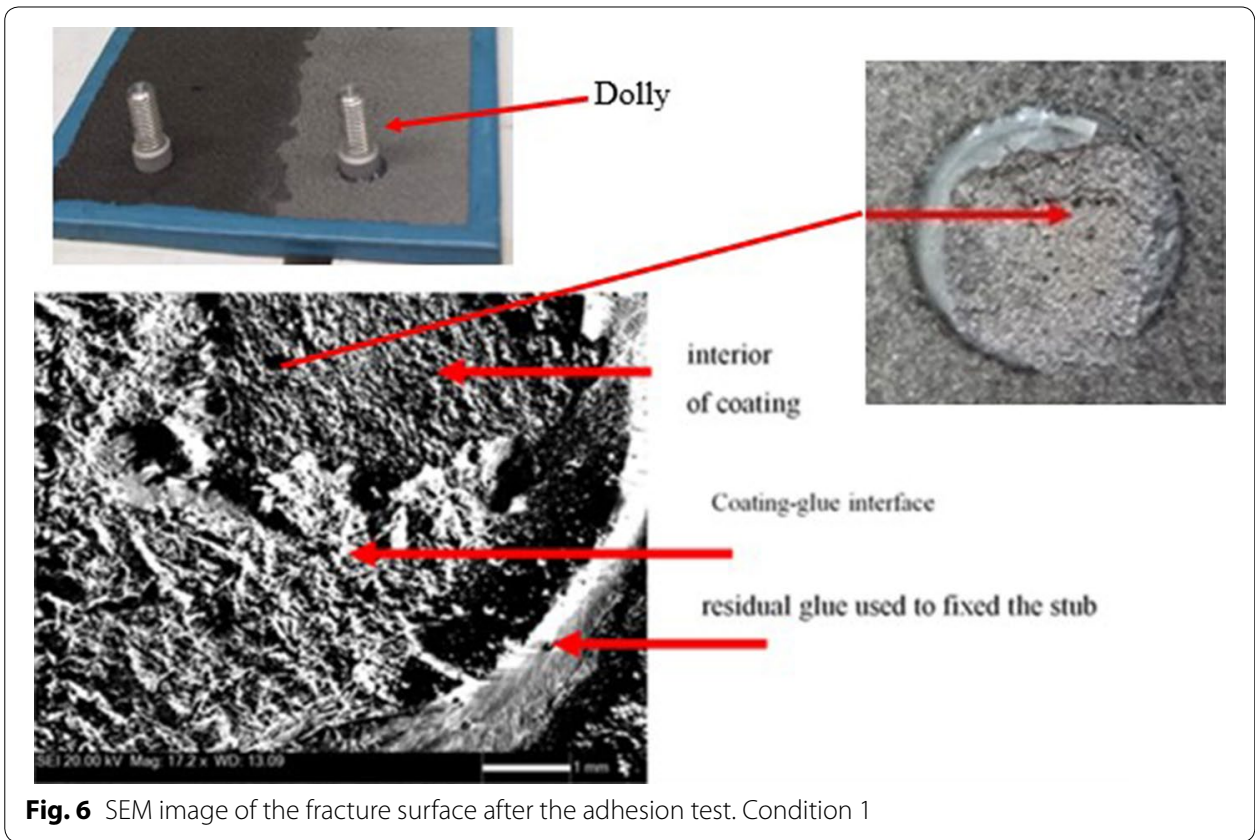

The quantitative measurements have revealed alpha and gamma $\mathrm{Fe}-\mathrm{Cr}$ alloy phases with the formation of a third one, chromite, $\mathrm{FeCr}_{2} \mathrm{O}_{4}$. The specific ICSD (Inorganic Crystals Structure Database) files used for the Rietveld calculations are ICSD102751 for the gamma Fe-Cr alloy, ICSD 102,748 for the alpha Fe-Cr alloy, and ICSD 171,121 for chromite. The goodness of fitting calculation is 1.257 for Condition 1 and 1.678 for Condition 2, which indicates a reasonable adjustment for the experimental data. The weight concentrations for the three phases are the same for Conditions 1 and 2 .

Figure 6 exhibits the aspect of alloy coating surfaces after the pull-off test. The adhesive strength of coatings appears slightly dependent on the chemical composition. $\mathrm{FeCr}$ and $\mathrm{CoCr}$ alloys' adhesive strength ranged from 24.9 to 29.7 MPa for both coatings, with an overall average adhesion tensile strength of $27.2 \mathrm{MPa}$. This strength is considerably higher than the typical mean values reported by Antunes et al. [10]. The prevalent mode of fracture of samples was adhesion failure, which is the fracture between the adhesive and the coating. Moreover, a high oxide content and microcracks can be observed in Fig. 2 (Condition 1). These microcracks are coating defects and can generate low adhesion and even low corrosion resistance [12].

Low porosity produces compact coatings and good substrate-coating bonds. Indeed, a close examination of the coating/substrate interface of deposit layers shows neither gaps nor cracks, which are characteristic features of good adhesion. The adhesion test metallic coating system presents good adherence of both interfaces (intermediate bond-deposit and intermediate bond-substrate).

The causes of adhesion failure are relevant to define the most sensitive areas and further improvements [20]. The deposit features change positively due to the affecting factors that produce heterogeneity, as substrate nature and even the workmanship. Moreover, during service, the corrosion provoked by the environment and the wear 


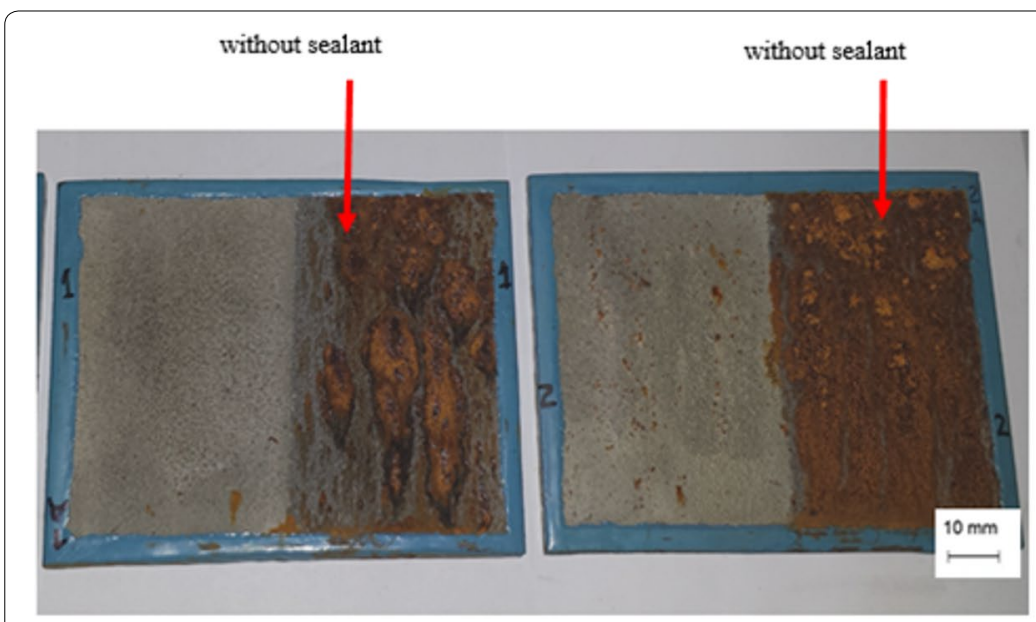

a

b

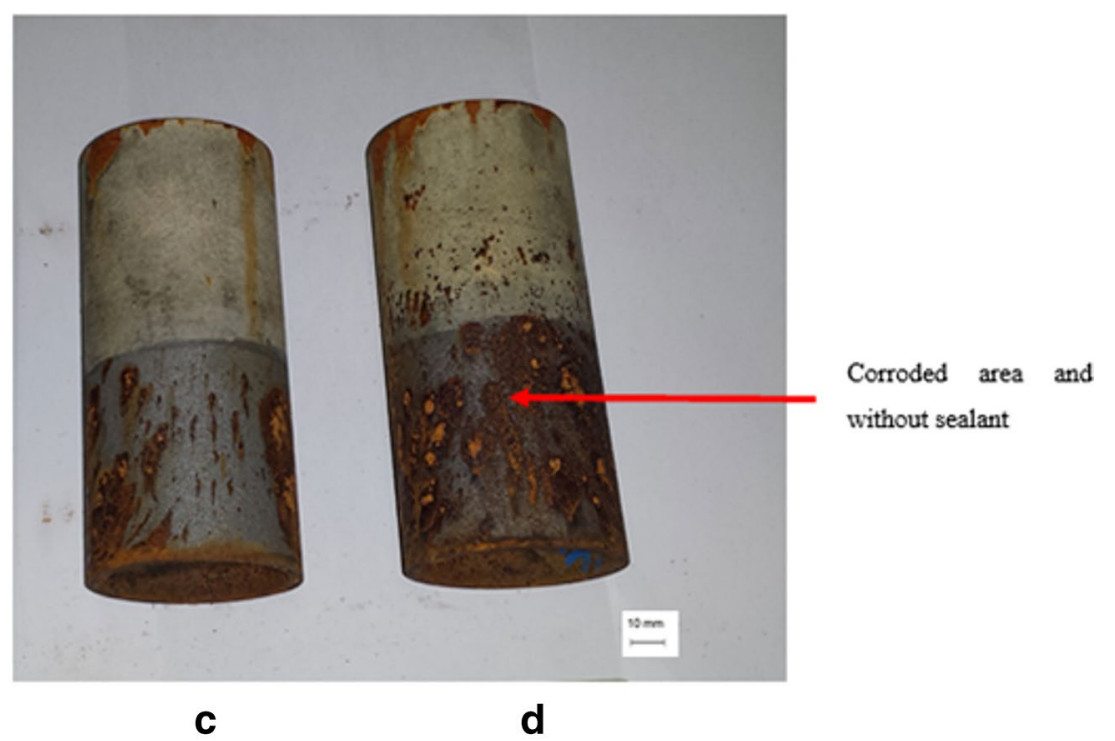

Fig. 7 Surface with/without sealant after the salt spray test. Plate: $\mathbf{a}$ Condition 1 and $\mathbf{b}$ Condition 2. Tube: $\mathbf{c}$ Condition 1 and $\mathbf{d}$ Condition 2

can reduce structures' lives. Thus, an evaluation of corrosion is necessary to obtain a corrosion resistance in representative media where the parts can operate.

Some samples were tested in a salt spray chamber for $36 \mathrm{~h}$ at $35^{\circ} \mathrm{C}$ to evaluate their resistance to corrosion in the presence of a chloride medium. After this exposition, all samples were gently cleaned with water and dried with hot air. Without sealant, the plate region with cobalt deposits shows the best results than the nickel and chromium-based alloys. In the relation of the machined tube samples, the results were similar to those found for the plates, i.e., better results with cobalt alloy. Figure 7 shows the surface of coatings without/with a sealant after the salt spray test, and the samples with epoxy sealant show negligible corrosion. Hence, the lack of corrosion of epoxy-coated samples for the studied condition indicates that its presence assures 
a high resistance against corrosion on carbon steel. Even considering the negligible corrosion intensity, and below the quantification limit of the used method, the microscopic evaluation reveals that Condition 1 (with cobalt) exhibited the lowest corroded area. The exposure of samples in the salt spray chamber's aggressive condition can be used as a screening test for brine environment corrosion performance for unsealed/ sealed samples. The sealants infiltrated into the coating and the correspondent corrosion resistance are higher than those found in the unsealed coatings.

The coating's adhesion to the substrate relies predominantly on the mechanical bonding; thus, careful cleaning and pretreatment of the coated surface are essential. Sealing sprayed coatings serve primarily to fill the coating's pores and microcracks, which provides additional protection against corrosive media that would otherwise penetrate the base material by cracks of the coating, reducing the corrosion resistance. Thus, sealing is a protective layer that closes pores near the surface but does not form an effective coating film [21]. The efficiency of each sealant could be considered by its barrier capability (i.e., its capability of blocking a corrosive liquid to penetrate towards the interface coating/substrate) $[18,21]$.

Electrochemical measurements are an efficient method to analyze corrosion resistance of coatings [22, 23], and also allow to evaluate the coating porosity [24]. Figure 8 shows the evolution of the open circuit potential versus time. All samples exhibited a potential dropping at the beginning of immersion until reaching a stable plateau related to corrosion potential $\mathrm{E}_{\text {corr }}$. This behavior indicated that a steady-state of corrosion had been reached with the $2 \mathrm{~h}$ exposition. The depletion of dissolved oxygen by cathodic reaction at the metallic interface can reduce the potential. The sealed coatings always exhibit nobler corrosion potential than unsealed coatings, revealing lower corrosion. This feature was associated with forming a barrier layer over the pores with a metallic surface on the coating surface [25] that increases the corrosion resistance.

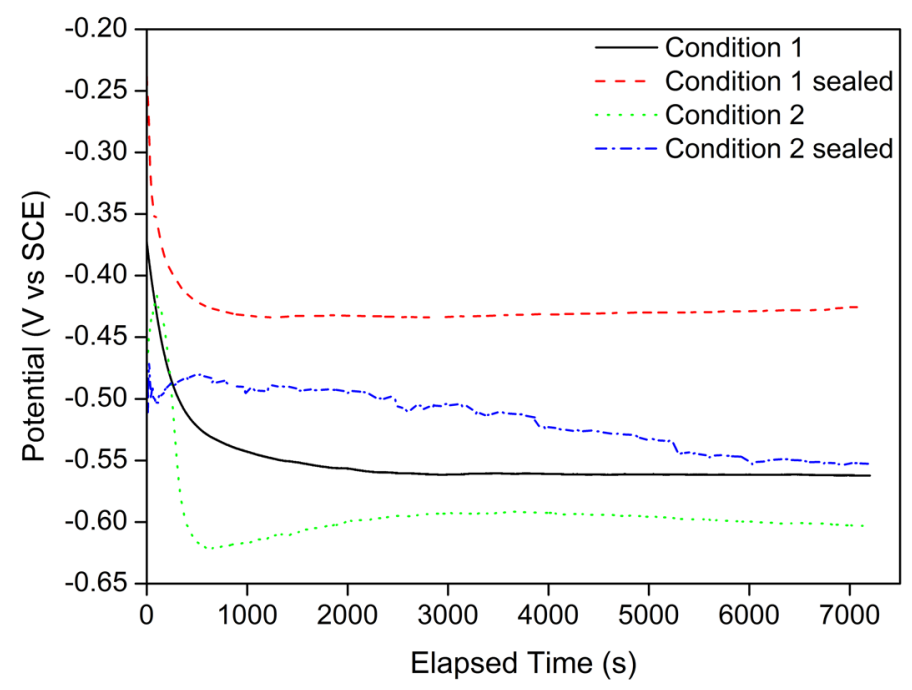

Fig. 8 Open circuit potential of sealed and unsealed coatings systems in 3.5\% wt. aqueous sodium chloride solution 


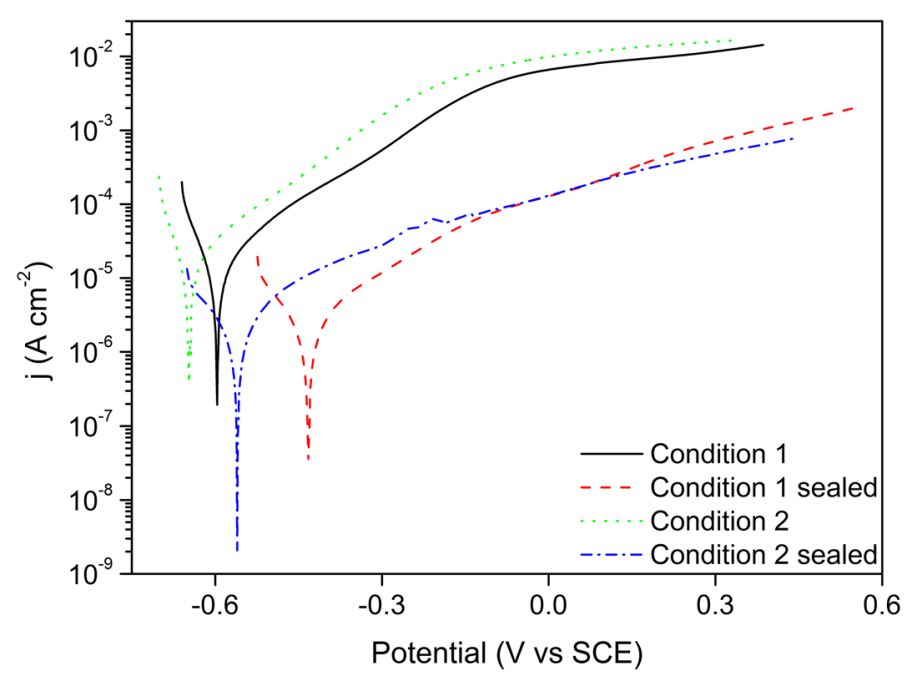

Fig. 9 Potentiodynamic polarization curves of sealed and unsealed coatings systems in 3.5\% wt. aqueous sodium chloride solution

Table 3 Corrosion parameters obtained from potentiodynamic polarization measurements obtained for the two coating conditions with and without sealant

\begin{tabular}{lccccc}
\hline & $\mathbf{E}_{\text {corr }}(\mathbf{m V}$ vs SCE$)$ & $\mathbf{J}_{\text {corr }}\left(\boldsymbol{\mu A} \cdot \mathbf{c m}^{\mathbf{2}}\right)$ & $\boldsymbol{\beta}_{\mathbf{c}}\left(\mathbf{m V} \cdot \mathbf{d e c}^{\mathbf{- 1}}\right)$ & $\boldsymbol{\beta}_{\mathbf{a}}\left(\mathbf{m V} \cdot \mathbf{d e c}^{\mathbf{- 1}}\right)$ & $\mathbf{S}_{\mathbf{i}}(\%)$ \\
\hline Condition 1 (CoCr) & & & & \\
Not sealed $-590.5 \pm 8.9$ & $14.0 \pm 1.0$ & $79.0 \pm 4.6$ & $155.8 \pm 4.0$ & - \\
Sealed & $-444.4 \pm 16.6$ & $3.0 \pm 0.2$ & $141.1 \pm 5.2$ & $154.0 \pm 26.7$ & $78.6 \pm 4.7$ \\
Condition 2 (FeCr) & & & & \\
Not sealed & $-651.9 \pm 6.9$ & $13.9 \pm 0.1$ & $59.9 \pm 2.8$ & $127.4 \pm 9.5$ & - \\
Sealed & $-560.7 \pm 0.1$ & $4.1 \pm 0.5$ & $227.5 \pm 5.5$ & $238.6 \pm 17.0$ & $70.50 \pm 2.4$ \\
\hline
\end{tabular}

The polarization curves for unsealed and sealed coatings in 3.5\% wt. sodium chloride electrolyte are shown in Fig. 9. The current density-potential shows an active process, with higher corrosion potential and lower current density for sealed specimens. The corrosion parameters calculated from Tafel extrapolation (i.e., corrosion potential $\mathrm{E}_{\text {corr }}$, corrosion current density $\mathrm{J}_{\text {corr }}$, cathodic $\beta_{\mathrm{c}}$, and anodic $\beta_{\mathrm{a}}$ Tafel slopes) are present in Table 3 . The corrosion current densities for the non-sealed samples are similar, regardless of the difference in the composition. Tafel slopes are related to the electrochemical mechanism of cathodic and anodic processes. However, as the tested alloys and coatings are complex, the straightforward interpretation of the values is a tricky task besides surfaces' morphology effect.

The electrochemical parameters can estimate the porosity $\mathrm{P}$ of the coating according to Eq. 1, take into account that the current comes chiefly from the active surface not sealed by the epoxy. P evaluates the coating's connected porosity through where the electrolyte reaches the metal, $j$ the corrosion current density of the unsealed surface, and $j_{\text {corrs }}$ is the corrosion current density of the sealed surface in the same electrolyte [18]. Once the porosity represents the coating's connected porosity, sealing treatments' effectiveness is related to a lower percentage of open porosity. Equation 2 

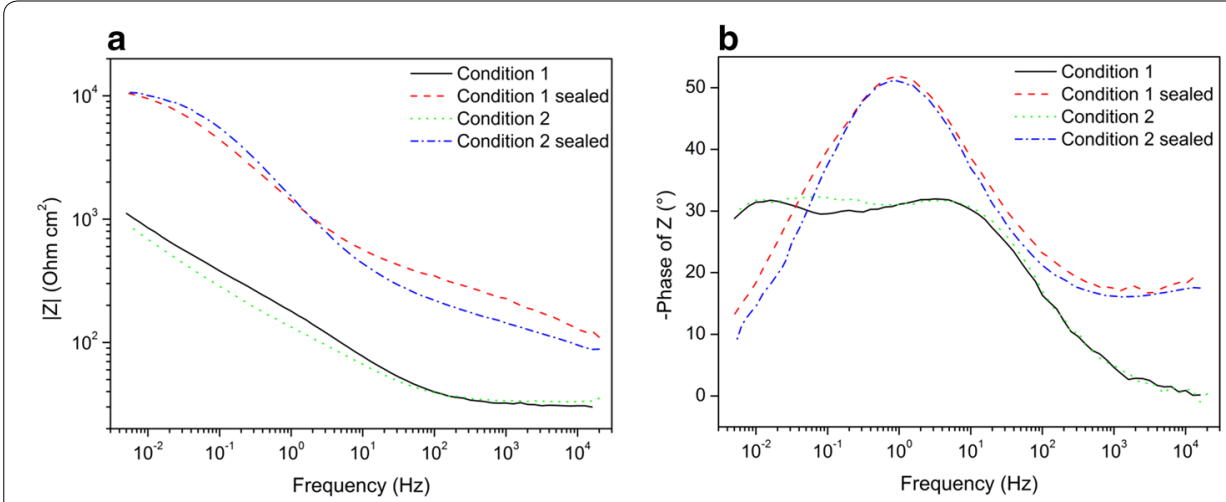

Fig. 10 Bode plot for EIS data for the sealed and unsealed coating conditions: a Impedance modulus and b Phase

can estimate the sealing efficiency, $S_{e}$ [26-30]. The porosity of Conditions 1 and 2 are, respectively, 21 and $29 \%$. These values are higher than those obtained by optical microscopy because the corrosion current can penetrate through tortuous paths not sensitive to detected by image analysis.

$$
\begin{aligned}
& P(\%)=100 \frac{j_{\text {corrs }}}{j_{\text {corrus }}} \\
& S_{e}(\%)=100\left(1-\frac{j_{\text {corrs }}}{j_{\text {corrus }}}\right)
\end{aligned}
$$

The calculated sealing efficiencies of coated samples are present in Table 3. For Condition 1 , the sealant was more effective $(78.6 \pm 4.7 \%)$ than from Condition 2 $(70.5 \pm 2.4 \%)$. As the corrosion current densities of unsealed coating are well similar, the efficiency relies on the lower current of epoxy sealed surfaces.

The EIS spectra measured at corrosion potential are displayed as Bode plots in Fig. 10. Grosso modo, the sealant increases tenfold the impedance modulus for both conditions in the major part of the frequency range (Fig. 10a). The maximum angle is also higher in the sealed sample than unsealed ones. Although the precise relationship between the corrosion current density and electrochemical impedance is complicated, generally, higher impedance modulus is associated with the higher corrosion resistance of the surface. EIS data are dependent on the surface area; then, the unsealed samples have a higher active area that produces lower impedance modulus. In this case, a positive effect of epoxy is the reduction of the active surface.

Moreover, the actual TS surface is difficult to evaluate; thus, we used a large sample area to reduce the possible influence on measurement and obtain a representative response from the surface. However, this phase reveals the presence of more than one electrochemical process. It is worth noting that unsealed samples exhibit at least two relaxation processes, clearly shown in angle phase (Fig. 10b), and likely also related to open porous. The low-frequency loop around $20 \mathrm{MHz}$ is just observed for unsealed 
samples, and likely it is related to surface imperfections. Probably the sealant covers the coating regions whose electrochemical response occurs close to $20 \mathrm{MHz}$. The low frequency can be ascribed to processes in a confined area such as pores or even a slow corrosive process, where the diffusion of species can play a role in the electrochemical process. This behavior is not related to the surface area, but other physical phenomena, such as diffusion and the localized corrosion processes. The critical effect of epoxy is blocking the sites where these processes occur, increasing the overall corrosion resistance. The observed microcracks and porosities can be sites responsible for the low-frequency loop. The high capillarity of the used resin enters the confined region and blocks the electrolyte's access, avoiding the corrosive attack.

Moreover, as cobalt is costly, its effect deserves to be further understanding in the microstructure and corrosion results. The cobalt increases the corrosion potential for an unsealed and sealed sample, but the corrosion current density is not significantly modified, but Tafel slopes. Similar results were observed in impedance diagrams. Hence, it is not possible to ascribe to the cobalt itself a specific improvement of the corrosion resistance. In the obtained data, the main effect was caused by the epoxy sealant that improves the corrosion resistance for this work's studied conditions.

\section{Conclusions}

The adhesive strength of coatings has been studied using the thermal spray process for two chemical compositions of wire and intermediate bonds on carbon steel. Further, the coatings were characterized by adhesion, corrosion, morphology, and crystallographic aspects. Moreover, the most relevant conclusions are summarized as follows:

1) Good uniformity of deposited layer with small oxides were obtained. The two studied conditions produced very few total defects (3.88\% for $\mathrm{CoCr}$ and $3.28 \%$ for $\mathrm{FeCr}$ ).

2) X-ray diffraction with Rietveld calculations revealed that both coating conditions produced the same final phases, a mixture of alpha and gamma $\mathrm{Fe}-\mathrm{Cr}$ alloy with chromite phase.

3) The coating termed Condition $1(\mathrm{FeCr}+\mathrm{CoCr}$ deposited alloy with $95 \mathrm{Ni} 5 \mathrm{Al}$ intermediate bond) resulted in the best average performance considering the microstructure, corrosion resistance in salt spray exposure, and the adhesion aspects. The samples with epoxy sealant presented a higher resistance against corrosion. However, the wire with higher cobalt content did not exhibit a significative better performance in the corrosion test than the chromium alloy.

4) The measured bond strength varied in the range 24.9-29.7 MPa for both conditions ( $\mathrm{FeCr}$ and $\mathrm{CoCr}$ ), with an overall average adhesion tensile strength of $27.2 \mathrm{MPa}$. The prevalent mode of fracture of samples was adhesion failure along with the adhesive and the coating interface. 


\section{Abbreviations}

TS: Thermal spray process; UNS: Unified numbering system; OM: Optical microscopy; SEM: Scanning electron microscopy; XRD: X-ray diffraction; EDX: X-ray energy-dispersive system; SCE: Saturated calomel electrode; OCP: Open circuit potential; EIS: Electrochemical impedance spectroscopy.

\section{Acknowledgments}

The authors would like to thank CNPq and FAPERJ. This study was financed in part by the Coordenação de Aperfeiçoamento de Pessoal de Nível Superior-Brasil (CAPES) —Finance Code 001.

\section{Authors' contributions}

MRDC, BCF, and IBDB participated in the experiments, JBC has performed the $x$-ray diffraction analysis and the writing of the manuscript, INB has performed the corrosion test and the data analysis and the writing of the manuscript, and HRMC has performed the SEM measurements, the coating experiments and the writing of the manuscript. All authors read and approved the final manuscript.

\section{Funding}

No funding has been provided for the research associated with this article.

\section{Availability of data and materials}

All relevant data is presented in the manuscript, and additional information can be made available on request if necessary.

\section{Competing interests}

The authors declare that they have no known competing financial interests or personal relationships that could have appeared to influence the work reported in this paper.

\section{Author details}

${ }^{1}$ Graduate Program in Mechanical Engineering and Materials Technology, Centro Federal de Educação Tecnológica Celso Suckow da Fonseca, Av. Maracanã, 229, Rio de Janeiro, RJ 20.271-110, Brazil. ${ }^{2}$ Instituto Politécnico, Universidade do Estado do Rio de Janeiro, Rua Bonfim, 25, Nova Friburgo, Rio de Janeiro, RJ 28.625-570, Brazil. ${ }^{3}$ Departamento de Engenharia Mecânica, Universidade do Estado do Rio de Janeiro, Rua Fonseca Teles, 121, São Cristóvão, Rio de Janeiro, RJ 20.940-903, Brazil.

Received: 17 August 2020 Accepted: 17 September 2020

Published online: 24 September 2020

\section{References}

1. Taheri K, Elhoriny M, Plachetta M, Gadow R. Thermodynamic analysis of resources used in thermal spray processes: energy and exergy methods. Entropy. 2016;18(7):237.

2. Hsu WL, Murakami H, Yeh JW, Yeh AC, Shimoda K. On the study of thermal-sprayed $\mathrm{Ni}_{0.2} \mathrm{CO}_{0.6} \mathrm{Fe}_{0.2} \mathrm{CrSi}_{0.2} \mathrm{AlTi}_{0.2} \mathrm{HEA}$ overlay coating. Surf Coat Technol. 2017;316:71-4.

3. Saravanan S, Ravichandran M, Balasubramaniyan V. Comparison studies on effect of thermal spray coating in internal combustion engine. MechMechEng. 2016;20(1):23-322.

4. Silva DP, Churiaque C, Bastos IN, Sánchez-Amaya JM. Tribocorrosion study of ordinary and laser-melted Ti6Al4V alloy. Metals. 2016;6(10):253.

5. Wielage B, Hofmann U, Steinhauser S, Zimmermann G. Improving wear and corrosion resistance of thermal sprayed coatings. Surf Eng. 1998;14(2):136-8.

6. Chen H, Zhou K, Jin Z, Liu C. Diffusion and phase transformation on interface between substrate and NiCrAlY in Y-PSZ thermal barrier coatings. J Therm Spray Technol. 2004;13(4):515-20.

7. Nicolaus M, Möhwald K, Maier HJ. Regeneration of high pressure turbine blades. Development of a hybrid brazing and aluminizing process by means of thermal spraying. ProcediaCIRP. 2017;59:72-9.

8. Ali O, Ahmed R, Faisal NH, Alanazi NM, Berger LM, Kaiser A, Toma FL. Influence of post-treatment on the microstructural and tribomechanical properties of suspension thermally sprayed WC-12 wt\% Co nanocomposite coatings. TribolLett. 2017;65(33):1-27.

9. Kawaguchi Y, Miyazaki F, Yamasaki M, Yamagata Y, Kobayashi N, Muraoka K. Coating qualities deposited using three different thermal spray technologies in relation with temperatures and velocities of spray droplets. Coatings. 2017;7:27.

10. Antunes FJ, Sá Brito VRS, Costa HRM, Bastos IN, de Campos JB, de Aguiar RAA. Correlation between chemical composition and adherence of $\mathrm{Cr}$ and Co coatings deposited by electric arc. J Adhes. 2015;91:754-67.

11. Sá Brito VRS, Bastos IN, Costa HRM. Corrosion resistance and characterization of metallic coatings deposited by thermal spray on carbon steel. Mater Des. 2012;41:282-8.

12. Schorr BS, Stein KJ, Marder AR. Characterization of thermal spray coatings. Mater Charact. 1999;42:93-100.

13. ASTM International. Standard test method for pull-off strength of coatings using portable adhesion testers. West Conshohocken: ASTM International; 2017. https://doi.org/10.1520/D4541-17.

14. Young RA. The Rietveld Method. Oxford: Oxford Press; 1995.

15. Cheary RW, Coelho A. A fundamental parameters approach to X-ray line-profile fitting. J ApplCryst. 1992;25:109-21.

16. Wang Y, Chen W. Microstructures, properties and high-temperature carburization resistances of HVOF thermal sprayed NiAl intermetallic-based alloy coatings. Surf Coat Technol. 2004;183:18-28.

17. Wang Y, Chen W, Wang L. Micro-indentation and erosion properties of thermal sprayed NiAl intermetallic-based alloy coatings. Wear. 2003;254:350-5. 
18. Liscano S, Gil L, Staia MH. Effect of sealing treatment on the corrosion resistance of thermal-sprayed ceramic coatings. Surf Coat Technol. 2004;188-189:135-9.

19. Desphpande T, Sampath S, Zhang H. Mechanisms of oxidation and its role in microstructural evolution of metallic thermal spray coatings - Case study for Ni-Al. Surf Coat Technol. 2006;200:5395-406.

20. Ramos NMM, Simões ML, Delgado JMPQ, de Freitas VP. Reliability of the pull-off test for in situ evaluation of adhesion strength. Constr Build Mater. 2012;31:86-93.

21. Wielage B, Hofmann U, Steinhauser S, Zimmermann G. Improving wear and corrosion resistance of thermal sprayed coatings. Surf Eng. 1998;14:136-8.

22. Neddemeyer T, Mocker M, Faulstich M. A new approach to improve high temperature corrosion resistance of thermally sprayed coatings by using electrochemical corrosion tests. Mater Corros. 2011;62(7):623-34.

23. Hoffmann R, Vreijling MPW, Ferrari GM, de Wit JHW. Electrochemical methods for characterisation of thermal spray corrosion resistant stainless steel coatings. Mater Sci Forum. 1998;289-292(2):641-54.

24. Jiménez H, Olaya JJ, Alfonso JL, Mtshali CR, Pineda-Vargas CA. Corrosion resistance of Ni-base WC/Co coatings deposited by spray and fuse process varying the oxygen flow. J Therm Spray Tech. 2017;26:1708-19.

25. Liu Z, Yan D, Dong Y, Yang Y, Chu Z, Zhang Z. The effect of modified epoxy sealing on the electrochemical corrosion behavior of reactive plasma-sprayed TiN coatings. CorrosSci. 2013;75:220-7.

26. Yu YJ, Kim JG, Cho SH, Boo JH. Plasma-polymerized toluene films for corrosion inhibition in microelectronic devices. Surf Coat Technol. 2003;162:161-6.

27. Nozawa K, Aramaki K. One- and two-dimensional polymer films of modified alkanethiol monolayers for preventing iron from corrosion. CorrosSci. 1999;41:57-73.

28. II-Cho P, Seong-Jong K. Complicated damage characteristics of cavitation and corrosion in sea water with sealing treatment for Al-3Mg arc sprayed coating. SciAdv Mater. 2018:10(1):104-8

29. Bolelli G, Colella A, Morelli S, Puddu P, Righetti E, Sassatelli P, Testa V. TiC-NiCr thermal spray coatings as an alternative to WC-CoCr and Cr3C2-NiCr. Wear. 2020;450-451(203273):1-23.

30. Pang $X$, Wang $R$, Wei $Q$, Zhou J. Effect of epoxy resin sealing on corrosion resistance of arc spraying aluminum coating using cathode electrophoresis method. Mater Res Express. 2018;5(1):016527.

\section{Publisher's Note}

Springer Nature remains neutral with regard to jurisdictional claims in published maps and institutional affiliations.

\section{Submit your manuscript to a SpringerOpen ${ }^{\odot}$ journal and benefit from:}

- Convenient online submission

- Rigorous peer review

- Open access: articles freely available online

- High visibility within the field

- Retaining the copyright to your article

Submit your next manuscript at $\mathbf{s p r i n g e r o p e n . c o m ~}$ 